\title{
Climate, ice sheets and sea level during past interglacial periods
}

\author{
Caroline Quanbeck', E. Capron ${ }^{2,3}$, S. Shackleton ${ }^{4}$ and J. McFarlin ${ }^{5}$ \\ PALSEA-QUIGS joint workshop, Galloway, NJ, USA, 24-27 September 2018
}

The goal of the first joint workshop held by the PALeo constraints on SEA level rise working group (PALSEA, pastglobalchanges. org/ini/wg/palsea/intro) and PAGES-PMIP Working Group on Quaternary Interglacials (QUIGS, pastglobalchanges.org/ini/wg/quigs/ intro) was to identify the state of our understanding on the interplay between climate, polar ice sheets and sea level during past interglacials.

The four-day meeting included three oral sessions with 26 talks, a poster session, an outreach event, a field excursion (Fig. 1), and two discussion sessions.

The first oral session focused on studies of climate, ice sheets, and sea level during the Last Interglacial (LIG). Converging evidence from marine, ice-core and terrestrial records indicate that high-latitude surface ocean temperatures were warmer by at least $1^{\circ} \mathrm{C}$ relative to pre-industrial and surface air temperatures by $>3-11^{\circ} \mathrm{C}$ (see Fischer et al. 2018 for a recent review). Recent developments in Earth system modeling, in the framework of PMIP4 (Otto-Bliesner et al. 2017), suggest vegetation and sea-ice feedbacks are key to reproducing LIG surface air warmth at the amplitude observed in paleoclimate records. Large uncertainties remain regarding the timing and extent of mass loss from the

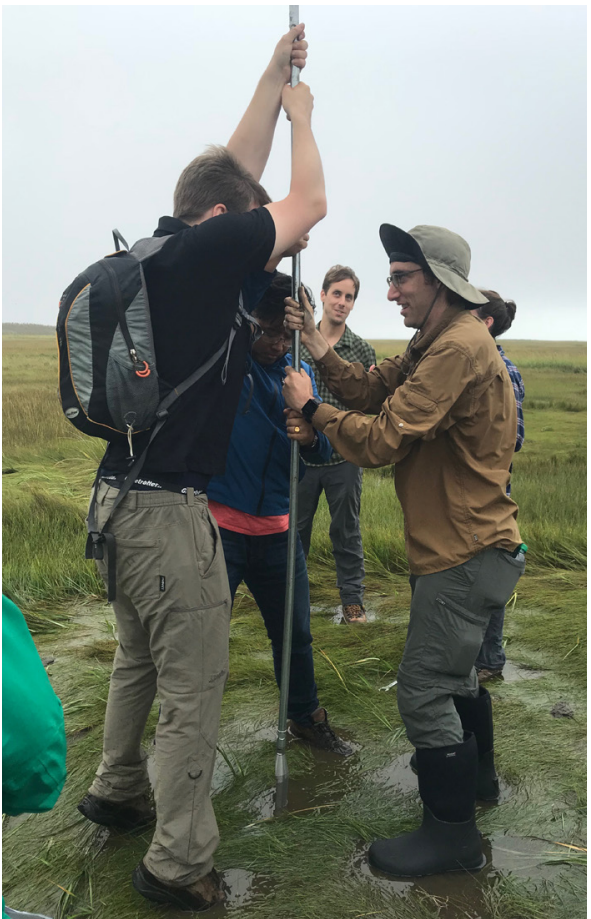

Figure 1: PALSEA-QUIGS scientists coring a salt marsh on the New Jersey coast. Data from salt marshes yield high-resolution records of Holocene sea-level change. Image credit: Robert Kopp.
Greenland and Antarctic ice sheets and their total respective contributions to the higherthan-present global sea level throughout the LIG.

The second oral session focused on climate, ice sheets, and sea level during even older interglacials, particularly Marine Isotope Stages (MIS) 11, 13 and 31. Recent work has indicated there are differences in the spatiotemporal expression and amplitude of climatic changes across interglacials. Challenges identified during the workshop include aligning proxy records chronologically, as well as an overall lack of well-dated sea-level benchmarks for these older interglacial periods.

The third oral session centered on Holocene sea level. Compared to earlier interglacials, the Holocene has the advantage that welldated archives of sea level are available in higher spatiotemporal resolution. This wealth of information allows for better constraints on processes that are also relevant to understanding sea level during older interglacials, such as glacial isostatic adjustment (GIA).

The meeting concluded with discussions dedicated to the identification of the most pressing areas where more research is needed. The key research questions identified include:

- How do interglacial sea-level highstands relate to interglacial temperatures in the high-latitudes, tropics, and globally?

-What determines the size of polar ice sheets in different interglacial climatic contexts?

Discussions primarily focused on the LIG, and emphasized a need for well-dated and highly-resolved climate and sea-level records for this time interval, as well as prior interglacials. Highlighted uncertainties included the rate of sea-level rise at the onset of the LIG, and the net amplitude of LIG global sea-level rise given potential hemispheric phasing of polar-ice-sheet growth and retreat. It was noted that constraining the ice-sheet configuration during the preceding glacial maxima has important implications for interglacial relative sea-level indicators because of the GIA effects.

The group also discussed the importance of using paleoclimate records to better characterize the structure (spatial and temporal) and amplitude of interglacial climate change in order to evaluate Earth system model simulations. This requires better spatial coverage of paleodata, particularly in the
Southern and Pacific Oceans. Finally, emphasis was placed on the need to find direct evidence for significant ice-mass loss both in Greenland and in Antarctica, which is crucial to constrain their respective contributions to LIG global sea level.

These key research questions will be summarized in an upcoming opinion paper for the broader paleo sea-level and paleoclimate communities, to encourage future work on the topics. The PALSEA and QUIGS working groups will continue to pursue collaboration through future joint initiatives (e.g. joint sessions at international meetings).

\section{ACKNOWLEDGEMENTS}

We thank the supporting organizations: PAGES, Rutgers University, the US National Science Foundation, and the International Union for Quaternary Research.

\section{AFFILIATIONS}

'Department of Geological Sciences, University of Florida, Gainesville, USA

${ }^{2}$ British Antarctic Survey, Cambridge, UK

${ }^{3}$ Centre for Ice and Climate, Niels Bohr Institute, University of Copenhagen, Denmark

${ }^{4}$ Scripps Institution of Oceanography, University of California San Diego, La Jolla, USA

${ }^{5}$ Department of Earth and Planetary Sciences,

Northwestern University, Evanston, IL, USA

\section{CONTACT}

Caroline Quanbeck: cquanbeck94@ufl.edu

\section{REFERENCES}

Fischer H et al. (2018) Nat Geosci 11: 474-485

Otto-Bliesner B et al. (2017) Geosci Model Dev 10 $3979-4003$ 